Pesq. Vet. Bras. 29(5):439-444, maio 2009

\title{
Caracterização fenotípica e molecular de amostras de Burkholderia mallei isoladas na Região Nordeste do Brasil ${ }^{1}$
}

\author{
Karla P.C. Silva ${ }^{2}$, Rinaldo A. Mota ${ }^{3 \star}$, Arildo P. Cunha ${ }^{3}$, Leonildo B.G. Silva ${ }^{3}$, \\ Nilma C. Leal ${ }^{4}$, Yoni V.N. Cavalcante ${ }^{5}$, José A.A. Teles ${ }^{3}$, Maria C.C. Pereira ${ }^{5}$ e \\ Nara S. Freitas ${ }^{5}$
}

\begin{abstract}
Silva K.P.C., Mota R.A., Cunha A.P., Silva L.B.G., Leal N.C., Cavalcante Y.V.N., Teles J.A.A., Pereira M.C.C. \& Freitas N.S. 2009. [Phenotypic and molecular characterization of Burkholderia mallei isolated in northeastern Brazil.] Caracterização fenotípica e molecular de amostras de Burkholderia mallei isoladas na Região Nordeste do Brasil. Pesquisa Veterinária Brasileira 29(5):439-444. Departamento de Medicina Veterinária, Universidade Federal Rural de Pernambuco, Dois Irmãos, Recife, PE 52171-900, Brazil. E-mail: rinaldo.mota@ hotmail.com

The objective of this paper was to study the molecular performance and phenotypic characterization of Burkholderia mallei isolated from horses with clinical and serological diagnosis of glanders, originating from the Metropolitan District of Recife and Zona da Mata of Pernambuco and Alagoas. The isolation and biochemical identification of $B$. mallei was carried out by microbiological and molecular techniques of PCR-fingerprinting and RAPD-PCR. From the eight samples studied, four showed little phenotype variations. In the molecular tests, the samples formed 4 groups of different ribotype profiles and 4 genotype profiles. There was some association of PCR-fingerprinting with RAPD-PCR results. It was concluded that the slight biochemical variations were not associated with different molecular profiles. They also indicated that these differences show heterogeneity associated with the origin of the sample, indicating that the infection was caused by clones of different strains and that the polymorphism of DNA observed could make it difficult to choose one standard strain for an immune prophylactic treatment of glanders.
\end{abstract}

INDEX TERMS: Burkholderia mallei, glanders, PCR-fingerprinting, RAPD-PCR.

RESUMO-- Objetivou-se com este trabalho realizar o estudo bioquímico e molecular de amostras de Burkholderia mallei isoladas de eqüídeos com diagnóstico clínico e sorológico para o mormo e provenientes da Região Metropolitana do Recife-PE e Zona da Mata dos Estados de Alagoas e Pernambuco. Foram realizadas as técnicas microbiológicas para o isolamento e identificação fenotí-

\footnotetext{
${ }^{1}$ Recebido em 3 de outubro de 2008.

Aceito para publicação em 30 de janeiro de 2009.

2 Departamento de Medicina Veterinária, Universidade Federal de Alagoas, Rua Camarão 17, Praia do Francês, Marechal Deodoro, AL 57160000, Brasil. *Autor para correspondência: rinaldo.mota@ hotmail.com

${ }^{3}$ Departamento de Medicina Veterinária, Universidade Federal Rural de Pernambuco (UFRPE), Dois Irmãos, Recife, PE 52171-900, Brasil.

${ }^{4}$ Departamento de Biologia, UFRPE, Dois Irmãos, Recife, PE.

${ }^{5}$ Departamento de Microbiologia, Centro de Pesquisa Aggeu MagaIhães, Cidade Universitária, Recife, PE 5067042.
}

pica de B. malleie as técnicas moleculares de ribotipagemPCR e RAPD-PCR. Das oito amostras estudadas, quatro apresentaram pequenas variações fenotípicas. Nas técnicas moleculares, as amostras formaram quatro grupos de diferentes perfis ribotípicos, demonstrando também quatro perfis genotípicos. Houve associação nos resultados da Ribotipagem-PCR e RAPD-PCR. As variações nos perfis ribotípicos e genotípicos foram associadas às diferentes regiões estudadas. De acordo com os resultados obtidos, conclui-se que as pequenas variações bioquímicas não estão associadas aos diferentes perfis moleculares e que essas diferenças demonstram uma heterogeneidade que está associada à procedência das amostras, indicando que a infecção nos animais ocorre por clones diferentes das amostras analisadas.

TERMOS DE INDEXAÇÃO: Burkholderia mallei, mormo, Ribotipagem-PCR, RAPD-PCR. 


\section{INTRODUÇÃO}

O mormo é uma das mais antigas doenças dos eqüídeos, descrita por Aristóteles e Hipócatres nos séculos 3 e 4 a.C. (Blancou 1994). É uma enfermidade infecto-contagiosa, de caráter agudo ou crônico que acomete principalmente os eqüídeos, podendo também acometer o homem, os carnívoros e eventualmente os pequenos ruminantes. Responsável por alta morbidade e letalidade, ocorre em diferentes partes do mundo (Dungworth 1993).

A doença foi descrita pela primeira vez no Brasil em 1811, introduzida, provavelmente por animais infectados e importados da Europa (Pimentel 1938). Após um período de aproximadamente 40 anos sem registros da doença no país, Mota et al. (2000), relataram os aspectos microbiológicos, epidemiológicos, clínicos, patológicos e de diagnóstico em eqüídeos dos estados de Pernambuco e Alagoas.

Os sinais clínicos observados nos animais doentes são febre, tosse e corrimento nasal, com evolução rápida das lesões para úlceras disseminadas na mucosa nasal e nódulos na pele da extremidade dos membros ou no abdome. Na forma crônica, observa-se pneumonia com tosse, epistaxe e dispnéia; lesões no septo nasal, que se iniciam com nódulos e evoluem para úlceras que após o processo de cicatrização formam cicatrizes em forma de estrelas; no início há uma secreção nasal serosa que evolui para purulenta com estrias de sangue. Observam-se, também, nódulos elevados de consistência firme a flácida na pele que drenam uma secreção purulenta amarelada (Pritchard et al. 1995, Sharrer 1995, Mota et al. 1999).

O diagnóstico consiste na associação dos aspectos clínico-epidemiológicos, anátomo-histopatológicos, isolamento bacteriano, prova biológica (inoculação em animais de laboratório), reação imunoalérgica (maleinização) e provas sorológicas como a fixação de complemento e ELISA (Al-Ani et al. 1998).

Alguns estudos estão sendo desenvolvidos com o objetivo de produzir uma vacina eficaz para o mormo uma vez que o tratamento dos animais não é recomendado. Amemiya et al. (2002) produziram uma vacina experimental com patogenicidade diminuída por irradiação da cápsula de polissacarídeo de Burkholderia mallei, sendo avaliada em ratos, não oferecendo proteção contra as amostras patogênicas do tipo selvagem de $B$. mallei. Análises moleculares de ácidos nucléicos são agora os métodos de eleição para caracterização dos microrganismos. Esses métodos são amplamente aceitos, devido ao desenvolvimento de técnicas de separação molecular altamente discriminatórios, a disponibilidade de programas analíticos computadorizados e a virtual exploração da tecnologia dos ácidos nucléicos com o desenvolvimento de técnicas de sondas e amplificação (Selender et al. 1986). Algumas técnicas mostram elevado potencial para tipificação ou subtipificação de isolados bacterianos com propósitos epidemiológicos, entre estas técnicas está a ribotipagem. A análise do rRNA 16S-23S pode ser utilizada para identificar novas espécies de microrganismos ou verificar a relação entre estes, porque esses genes são altamente conservados dentro de uma espécie (Collier et al. 1996, Grattard et al. 1996, Mattar et al. 1996, Sorroel et al. 1996).

O polimorfismo de DNA por amplificação aleatória (RAPD) tem sido empregado para estudos genéticos de isolados de B. mallei (Leelayuwat et al. 2000). Outras análises gênicas vêm sendo realizadas utilizando esta técnica, por exemplo, mapeamentos genéticos, análises filogenéticas, estudos populacionais e tipificação molecular de vários microrganismos (Welsh \& McClelland 1990, Lawrence et al. 1993, Kurata et al. 1994, Chen \& Chen 1995, Debast 1995). Várias investigações podem ser realizadas utilizando o RAPD, no entanto a técnica é viável se as condições do PCR forem otimizadas (Benter et al. 1995), podendo ser aplicada de forma mais eficaz na identificação de similaridades genéticas ou diferenças no genótipo como um todo (Leelayuwat et al. 2000), de acordo com Campbell (2000), o RAPD é o método mais adequado para ser empregado em situações em que se tenham um grande número de amostras para serem analisadas. Os resultados do RAPD podem ser utilizados em conjunto com outros métodos para indicar ou confirmar diferenças entre amostras ou quando os resultados obtidos apenas no RAPD são ambíguos.

Existem algumas considerações referentes à reprodutibilidade do RAPD-PCR, devido ao anelamento aleatório de primer utilizados na técnica o qual pode refletir em amplificações variadas. A escolha do primer adequado para amplificar o polimorfismo do DNA bacteriano é um dos eventos importantes para validação do teste (Farber, 1996). Além disso, quando o primer representa em um grupo de espécie bacteriana uma boa reprodutibilidade, 0 RAPD-PCR destas amostras determina um polimorfismo padrão das espécies, sempre que forem adotadas as mesmas condições de PCR realizadas (Williams et al. 1990; Charlton et al. 1999).

Considerando a reemergência da doença no território nacional e a necessidade de contribuir para o estudo epidemiológico do mormo, objetivou-se realizar a caracterização fenotípica e molecular das amostras de $B$. mallei isoladas de eqüídeos com mormo nos Estados de Pernambuco e Alagoas.

\section{MATERIAL E MÉTODOS}

As amostras para o experimento foram colhidas de eqüídeos naturalmente infectados, provenientes de propriedades localizadas na Região Metropolitana e Zona da Mata de Pernambuco e de uma propriedade sediada na Zona da Mata de Alagoas.

Para a recuperação de Burkholderia mallei foram obtidas oito amostras de conteúdo de nódulos cutâneos fechados de oito eqüídeos distintos com a forma clínica da doença e sorologicamente positivos ao teste de fixação do complemento. As amostras para o diagnóstico microbiológico foram colhidas através de punção aspirativa e em seguida semeadas ágar sangue de ovino a $10 \%$ e em ágar batata glicerinado, incubadas a $37^{\circ} \mathrm{C}$ por 48 horas. As colônias foram identificadas por suas caracte- 


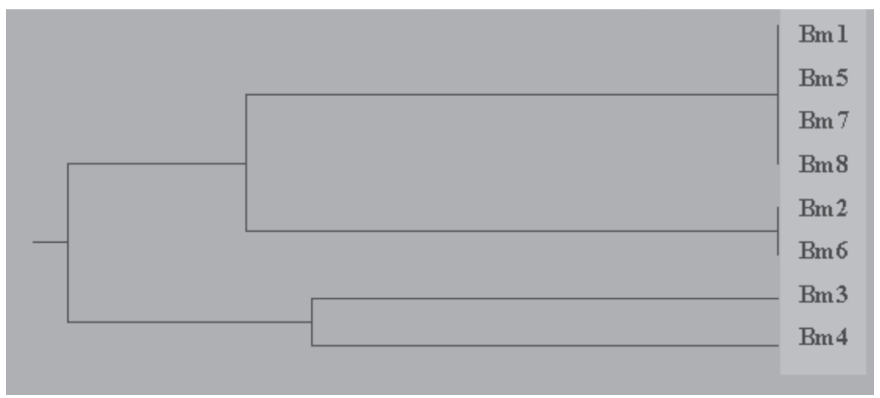

Fig.1. Dendrograma das amostras de Burkholderia malleia partir do perfil fenotípico dos biótipos identificados, utilizando o programa NTSYS-pc versão 1.7, usando o índice de Jaccard (medida de similaridade) e o gráfico Tree display.

rísticas morfotintorias e posteriormente submetidas às provas bioquímicas de catalase, oxidase, indol, produção de $\mathrm{H}_{2} \mathrm{~S}$, vermelho de metila, Voges Proskauer, motilidade, crescimento a $42^{\circ} \mathrm{C}$, produção de pigmento, lisina descarboxilase, gás de Dglucose, citrato, urease e fermentação de carboidratos (glicose, maltose, galactose, lactose, frutose, manose, sacarose e manitol), segundo Al-Ani et al. (1998).

Foi elaborada uma matriz pelas análises do comportamento fenotípico das amostras nas provas bioquímicas através do programa NTSYS-pc versão 1.7 usando o índice de Jaccard (medida de similaridade). A árvore com as cepas foi desenvolvida pelo gráfico Tree display (Fig.1).

Após a identificação bacteriana, as amostras de B. mallei foram repicadas em caldo Infusion Brain Heart $(\mathrm{BHI})$, incubadas em estufa a $37^{\circ} \mathrm{C}$ por 24 horas. Posteriormente, inoculou-se $0,1 \mathrm{~mL}$ da cultura em cobaios (Cavia porcelus) machos e adultos, por via intraperitoneal (prova de Strauss) segundo Langenegger et al. (1960), para confirmação da infecção, através da observação das lesões macroscópicas no testículo dos animais inoculados. As cepas bacterianas isoladas e identificadas como B. mallei foram mantidas congeladas em glicerol (80\%) a $-80^{\circ} \mathrm{C}$.

As amostras de $B$. mallei foram caracterizadas genotipicamente através das técnicas de Ribotipagem-PCR e o RAPDPCR. A extração de DNA dos isolados foi realizada conforme descrições de Sambrook \& Russel (2001). As amostras foram retiradas do estoque e semeadas em $5 \mathrm{~mL}$ de $\mathrm{BHI}$ e incubadas por 24 horas a $37^{\circ} \mathrm{C}$, posteriormente foram centrifugadas no volume de $1,5 \mathrm{~mL}$ durante três minutos em centrífuga para eppendorf a 13.000rpm. O sedimento obtido foi ressuspendido em $567 \mathrm{~mL}$ de TE $(10 \mathrm{mM}$ de Tris- $\mathrm{HCl}$ e $1 \mathrm{mM}$ de EDTA, $\mathrm{PH} 8,0)$ em $30 \mathrm{~mL}$ de SDS a $20 \%$ e $3 \mathrm{~mL}$ de proteinase $\mathrm{K}(20 \mathrm{mg} / \mathrm{mL})$, sendo a solução homogeneizada e incubada por 1 hora e 30 minutos a $37^{\circ} \mathrm{C}$. Depois da lise celular foi adicionado $500 \mathrm{~mL}$ de fenol-clorofórmio (1/1) e centrifugado por cinco minutos a 13.000rpm (operação repetida 5 vezes) com o objetivo de excluir as proteínas da solução. O precipitado resultante da centrifugação foi acrescido de 0,8 volumes de isopropanol e 0,1 volume de acetato de sódio $3 \mathrm{M} \mathrm{PH} \mathrm{5.2,} \mathrm{centrifugando-se} \mathrm{du-}$ rante 20 minutos e posteriormente o DNA precipitado foi lavado com $100 \mathrm{~mL}$ de álcool a $70^{\circ} \mathrm{Gl}$, centrifugado por cinco minutos e ressuspendido em 100-500mL de TER (10mM de Tris- $\mathrm{HCl}$ e $1 \mathrm{mM}$ de EDTA, PH 8,0 e RNAse). As amostras foram mantidas a $-20^{\circ} \mathrm{C}$ para visualização e quantificação do DNA em gel de agarose a $1 \%$.

As reações para a técnica de ribotipagem-PCR foram preparadas em um volume total de $25 \mathrm{~mL}$ por tubo, contendo 20ng de DNA genômico; $50 \mathrm{mM}$ de KCL e $10 \mathrm{mM}$ de Tris-HCL
$\mathrm{pH} 8 ; 0,16 \mathrm{mM}$ de cada desoxinucleotídeo trifosfato (dNTPAmersham Bioscience ); $1,5 \mathrm{mM}$ de $\mathrm{Mg} \mathrm{Cl}_{2} ; 20$ pmol de cada primer; $1 \mathrm{U}$ da enzima Taq DNA polimerase (Amersham Bioscience). Os primers descritos por Kostman et al. (1992) foram utilizados nas reações de PCR (5'-TTGTACACA CCGCCCGTA-3' e 5'-GGTACCTTAGATGTTTCAGTTA-3').

As misturas da reação foram cobertas com uma gota de óleo mineral e submetidas à amplificação em termociclador (Perkin Elmer) programado para 30 ciclos correspondendo cada ciclo a 1 minuto a 94을 para desnaturação do DNA, 1 minuto a 50 ㄷ $\mathrm{C}$ para anelamento dos primers e uma etapa do alongamento da fita de DNA, de 1 minuto a $72^{\circ} \mathrm{C}$, terminando com uma etapa de alongamento final de 7 minutos a $72^{\circ} \mathrm{C}$. Ao final das amplificações uma alíquota de $10 \mathrm{~mL}$ dos produtos obtidos em cada reação foi misturada com $3 \mathrm{~mL}$ do tampão de amostra (6 X concentrado) e submetido à eletroforese em gel de agarose a $1,5 \%$, nas condições já descritas, utilizando-se um marcador de peso molecular conhecido (100 base-pair DNA ladder, Amersham Bioscience).

Para a realização do polimorfismo de DNA foram testados 18 primers e realizado o RAPD-PCR teste de $B$. mallei. O primer selecionado e utilizado foi o 14 (5'-TGC CGA GCT G-3'), por ser que melhor amplificou as amostras testadas. As reações de PCR foram preparadas em volume final de $25 \mathrm{~mL}$ por tubo, contendo 20ng do DNA molde, Tris- $\mathrm{HCl} 10 \mathrm{mM}, \mathrm{KCl} 50 \mathrm{mM}$; $\mathrm{MgCl}_{2} 3,0 \mathrm{mM}$; 200mM de dNTP (Amersham Bioscience); 20pmol de cada iniciador (um par por cada tudo) e $2 \mathrm{U}$ da Taq polimerase (Amersham Bioscience). As amplificações foram feitas em termociclador Perkin Elmer, programado para 30 ciclos de 1 minuto a $94^{\circ} \mathrm{C}$ para a desnaturação, 1 minuto a $36^{\circ} \mathrm{C}$ para $\mathrm{O}$ anelamento e 2 minutos a $72^{\circ} \mathrm{C}$ para o alongamento das fitas de DNA, terminando por 7 minutos a $72^{\circ} \mathrm{C}$.

A reprodutibilidade dos resultados do RAPD foi determinada pela repetição da $\mathrm{PCR}$ por três vezes, em cada partida de amplificação foi incluído um controle negativo e um positivo da reação. O produto da amplificação foi submetido à eletroforese em gel de agarose a 1,5\%. Como padrão de peso molecular foi utilizado o "100 base-pair DNA ladder" (GIBCO-BRL-Invitrogen).

\section{RESULTADOS E DISCUSSÃO}

Os animais provenientes das propriedades da Região Metropolitana do Recife eram utilizados para tração e transporte de materiais das pequenas casas comerciais da construção civil. Os animais da Zona da Mata dos estados de Pernambuco e Alagoas eram provenientes de engenhos e utilizados na tração de carroças de cana-de-açúcar. Todas as propriedades visitadas apresentavam animais com sintomas de doença respiratória e linfática, caracterizada clinicamente por descarga nasal muco-purulenta (uni ou bilateral) em alguns casos com presença de estrias de sangue, úlceras na mucosa dos septos nasais, cicatrizes em forma de estrela na mucosa nasal, hipertermia, dispnéia, estertores pulmonares, debilidade, inapetência, cansaço ao realizar esforço físico, linfangite, nódulos subcutâneos firmes ou flutuantes ao longo do trajeto dos vasos linfáticos; alguns animais apresentaram ainda, edema dos membros posteriores e prepúcio além da caquexia nos casos crônicos da doença. Os achados clínicos observados neste estudo foram compatíveis com aqueles citados por Mota et al. (2000) e Rabelo et al. (2003). 
Quadro 1. Caracterização bioquímica das cepas de Burkholderia mallei isoladas de eqüídeos naturalmente infectados. Pernambuco, Brasil

\begin{tabular}{|c|c|c|c|c|c|c|c|c|}
\hline Bioquimismoa $^{a}$ & 01 & 05 & 07 & 08 & 02 & 06 & 03 & 04 \\
\hline Catalase & + & + & + & + & + & + & + & + \\
\hline Oxidase & + & + & + & + & + & + & + & + \\
\hline Indol & - & - & - & - & - & - & - & - \\
\hline $\mathrm{H} 2 \mathrm{~S}$ & - & - & - & - & - & - & - & - \\
\hline V.M. & - & - & - & - & - & - & - & - \\
\hline V.P. & - & - & - & - & - & - & - & - \\
\hline Motilidade & - & - & - & - & - & - & - & - \\
\hline Crescimento $42^{\circ} \mathrm{C}$ & + & + & + & + & + & + & + & + \\
\hline Producão de pigmento & - & - & - & - & - & - & - & - \\
\hline Lisina & + & + & + & + & + & + & + & + \\
\hline Gás de D-glucose & +1 & +1 & +1 & + & - & - & - & +1 \\
\hline Citrato & - & - & - & - & - & - & - & - \\
\hline Urease & - & - & - & - & - & - & - & - \\
\hline Glucose & + & + & + & + & + & + & + & + \\
\hline Maltose & - & - & - & - & - & - & - & - \\
\hline Galactose & $+/-$ & $+/-$ & + & $+/-$ & $+/-$ & $+/-$ & $+/-$ & + \\
\hline Lactose & - & - & - & - & - & - & - & - \\
\hline Fructose & - & - & - & - & - & - & - & - \\
\hline Manose & - & - & - & - & - & - & - & - \\
\hline Sacarose & - & - & - & - & - & - & - & $+/-$ \\
\hline Manitol & - & - & - & - & - & - & - & - \\
\hline
\end{tabular}

aV.M.= vermelho de metila; V.P.= Voges Proskauer; $\left(+^{\prime}\right)=$ levemente positivo; $(+/-)=$ mais que $80 \%$ positivo.

As amostras isoladas foram provenientes de diferentes bairros da Região Metropolitana do Recife e de municípios da Zona da Mata de Pernambuco e Alagoas. As oito amostras de Burkholderia mallei foram identificadas com o número de registro do laboratório de acordo com o período de seu isolamento em $B m 1, B m 2, B m 3, B m 4$, $\mathrm{Bm} 5, \mathrm{Bm}$ 6, Bm 7 e $\mathrm{Bm} 8$ (Fig.1). Os microrganismos foram caracterizados como bastonetes Gram-negativos, não esporulados, imóveis, aeoróbios, classificados através de testes bioquímicos como B. mallei (Quadro 1).

Todas as amostras inoculadas nos cobaios (Cavia porcellus) provocaram reação de Strauss positiva, comprovada pelo processo inflamatório testicular e posterior o re-isolamento da bactéria. Os achados em cobaios são compatíveis com aqueles relatados por Fritz et al. (2000) e Silva (2003) que estudaram a infecção experimental por B. mallei em hamsters e cobaios, respectivamente.

O comportamento fenotípico das amostras bacterianas identificadas apresentou pequenas variações em seu perfil, no que se refere à fermentação de alguns carboidratos como a galactose e produção de gás da D-glucose. Variações estas que não interferem na identificação bacteriana e que são referenciadas como resultado da fenotipagem de cepas de uma mesma espécie; semelhantes resultados foram encontrados por Al-Ani et al. (1998) e Silva (2003). Observou-se, também, variação na fermentação da sacarose e nenhuma cepa fermentou a maltose e o manitol, divergindo das amostras estudadas por Al-Ani et al. (1998) (Quadro 1).

De acordo com a divisão dos biotipos, em relação à similaridade fenotípica, os isolados $B m 1, B m 5, B m 7 e$ $B m$ 8, podem ser considerados idênticos; o mesmo ocor- reu com as cepas $B m 2$ e $B m$ 6, e isoladamente a $B m 3 e$ $B m$ 4. Entretanto os dados podem variar se observadas as análises de biologia molecular.

A Ribotipagem-PCR, utilizando primer segundo Kostmam et al. (1992), demonstrou padrão de amplificação dos oito biotipos de B. mallei pouco polimórfico, caracterizado por uma banda padrão de $1.000 \mathrm{pb}$. Segundo Tyler et al. (1995) e Bauernfeind et al. (1998), B. mallei apresenta apenas um operon e a amplificação de apenas uma banda da região intergênica 16S-23S rRNA é padrão para espécie, podendo ser observadas outras, de acordo com o polimorfismo das cepas. Conforme observado neste estudo, existiu uma relativa homologia entre a extensão da região espaçadora intergênica (ITS) de $B$. mallei e a ITS de Burkholderia pseudomallei, confirmando a similaridade de DNA em mais de $80 \%$ entre as duas espécies. De acordo com Bauernfeind et al. (1998), as amostras de $B$. mallei submetidas à ribotipagem-PCR geram produto de amplificação de $1.051 \mathrm{pb}$, servindo como modelo de rDNA da B. mallei e B. pseudomallei, mas não para outras espécies de Burkholderia sp.

As oito cepas analisadas demonstraram quatro perfis de ribotipagem distintos, sendo agrupadas como ribotipos 1 (R1), 2 (R2) 3 (R3) e o 4 (R4), pela observação de uma banda variante com $600 \mathrm{pb}$ para o $\mathrm{R} 1(\mathrm{Bm} 1)$, uma banda de $700 \mathrm{pb}$ para o R2 ( $\mathrm{Bm}$ 2) e uma de $800 \mathrm{pb}$ para o R3 $(B m 3)$; o perfil R3 não apresentou bandas variantes além da banda padrão (Fig.2). A identificação de poucas diferenças no rDNA 16S-23S, revelam pequena heterogeneidade nos biotipos estudados, observação também feita por Tyler et al. (1995) que comprovaram a heterogenei-

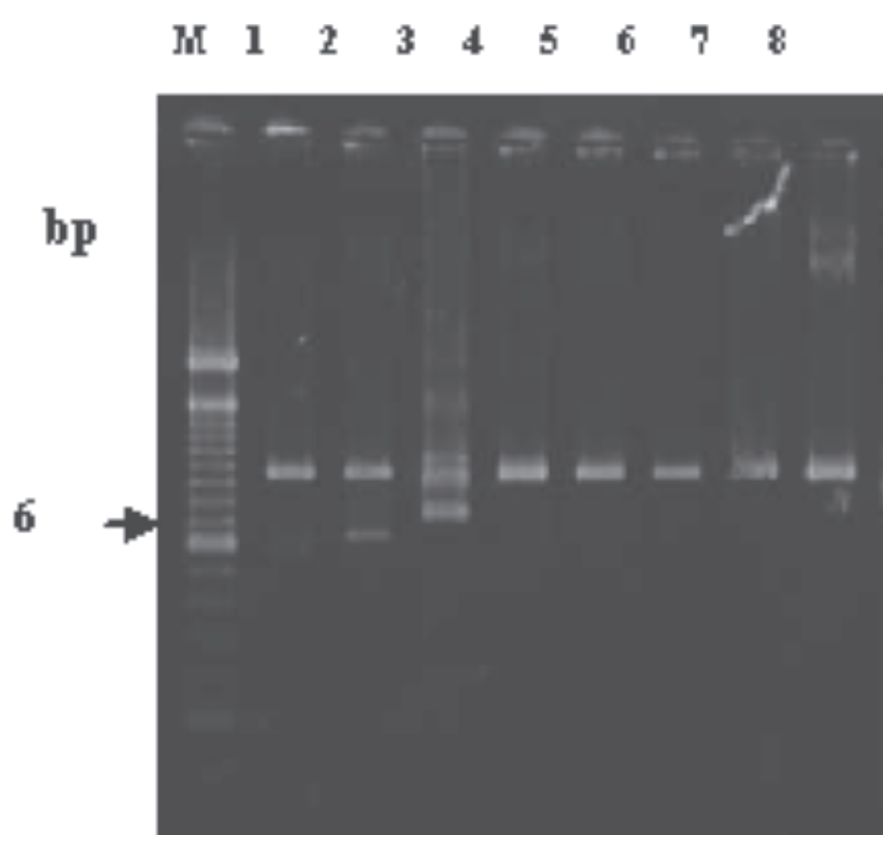

Fig.2. Gel de agarose 1,5\% dos produtos de amplificação de PCR das regiões espaçadoras intergênicas (ISRs). Linhas, $\mathrm{M}=$ "100 bp DNA ladder"; $1=B m$ 01; $2=B m$ 02; $3=B m 03$; $4=B m 04 ; 5=B m 05 ; 6=B m 06 ; 7=B m 07 ; 8=B m 08$. 
Quadro 2. Origem, características e distribuição regional das cepas de Burkholderia mallei

\begin{tabular}{cccccc}
\hline $\begin{array}{c}\text { № de } \\
\text { registro }\end{array}$ & $\begin{array}{c}\text { Fonte } \\
\text { (Espécie) }\end{array}$ & $\begin{array}{c}\text { Ano } \\
\text { (Isolamento) }\end{array}$ & $\begin{array}{c}\text { Foco) } \\
\text { (Cidade/Estado }\end{array}$ & $\begin{array}{c}\text { Ribotipo } \\
\text { (R) }\end{array}$ & $\begin{array}{c}\text { Genótipo } \\
\text { (G) }\end{array}$ \\
\hline Bm 1 & Muar & 2001 & Palmares, PE & $\mathrm{R} 1$ & $\mathrm{G} 1$ \\
$B m$ 2 & Muar & 2001 & Ipojuca, PE & $\mathrm{R} 2$ & $\mathrm{G} 2$ \\
$B m 3$ & Muar & 2002 & Cajueiro, AL & $\mathrm{R} 3$ & $\mathrm{G} 3$ \\
$B m$ 4 & Eqüíno & 2002 & Caxangá, PE & $\mathrm{R} 4$ & $\mathrm{G} 4$ \\
$B m 5$ & Eqüíno & 2002 & Areias, PE & $\mathrm{R} 4$ & $\mathrm{G} 4$ \\
$B m$ 6 & Eqüíno & 2002 & Areias, PE & $\mathrm{R} 4$ & $\mathrm{G} 4$ \\
$B m 7$ & Eqüíno & 2002 & Caxangá, PE & $\mathrm{R} 4$ & $\mathrm{G} 4$ \\
$B m$ 8 & Eqüíno & 2003 & Afogados, PE & $\mathrm{R} 4$ & $\mathrm{G} 4$
\end{tabular}

dade de B. pseudomallei que pode ser considerada como um diferencial para as duas espécies.

As variações bioquímicas não demonstraram associação com os grupos formados nos perfis ribotípicos (ribotipagem-PCR) e genotípicos (RAPD-PCR) (Quadro 2). As diferenças observadas não estão relacionadas, pois se baseiam em análises bacterianas diferentes, os resultados nas provas bioquímicas são expressão das características fenotípicas bacterianas (Al-Ani et al. 1998), a ribotipagem reflete a análise molecular do rRNA 16S-23S e o RAPD-PCR o polimorfismo do DNA bacteriano (Godoy et al. 2007). Entretanto os achados moleculares podem ser comparados com o perfil fenotípico das amostras e com outros dados epidemiológicos.

A genotipagem pelo polimorfismo de amplificação aleatória do DNA (RAPD-PCR) com o primer 14 (5'-TGC CGA GCT G-3') demonstrou em condições de baixa estringência uma amplificação de várias bandas entre 850 e >2000pb. Com uma banda padrão de amplificação para a espécie $>2000 \mathrm{pb}$ (para todas as cepas), a amostra Bm 3 , demonstrou grande pleomorfismo, confirmando o perfil da ribotipagem. Além da banda padrão foram observadas outras bandas variantes, o que tornou possível agrupar as cepas em quatro perfis genotípicos (G1, G2, G3 e G4). O perfil $\mathrm{G} 1(\mathrm{Bm} 1)$ apresentou duas bandas variantes de 1200 e 1400pb, o G2 (Bm 2) demonstrou uma banda variante acima de 1400pb; o G3 ( $\mathrm{Bm} 3$ ) apresentou bandas com $900 \mathrm{pb}$ e uma menor que 2000pb e por fim o G4 (Bm 4 - Bm 8) mostrou duas bandas de 1200 e 2000pb, respectivamente (Fig.3). O perfil genotípico confirmou as variações observadas na ribotipagem. Houve uma correspondência entre os diferentes perfis e a distribuição dos focos de infecção. As cepas originárias de focos localizados na Região Metropolitana do Recife foram agrupadas dentro de um mesmo ribotipo e apresentaram polimorfismo de DNA semelhante, enquanto que as cepas da Zona da Mata de Pernambuco e Alagoas exibiram ribotipos e perfis genotípicos diferentes.

Williams et al. (1990) e Wuthiekanum et al. (1996), relataram que as amostras de B. pseudomallei podem sofrer progressivas variações em seu genótipo, demonstrando diferenças em sua virulência. Essas variações podem ocorrer também em amostras de diferentes procedências e que do mesmo modo outras espécies do gênero Burkholderia podem sofrer pequenas alterações em seu genótipo.

\section{123345678}

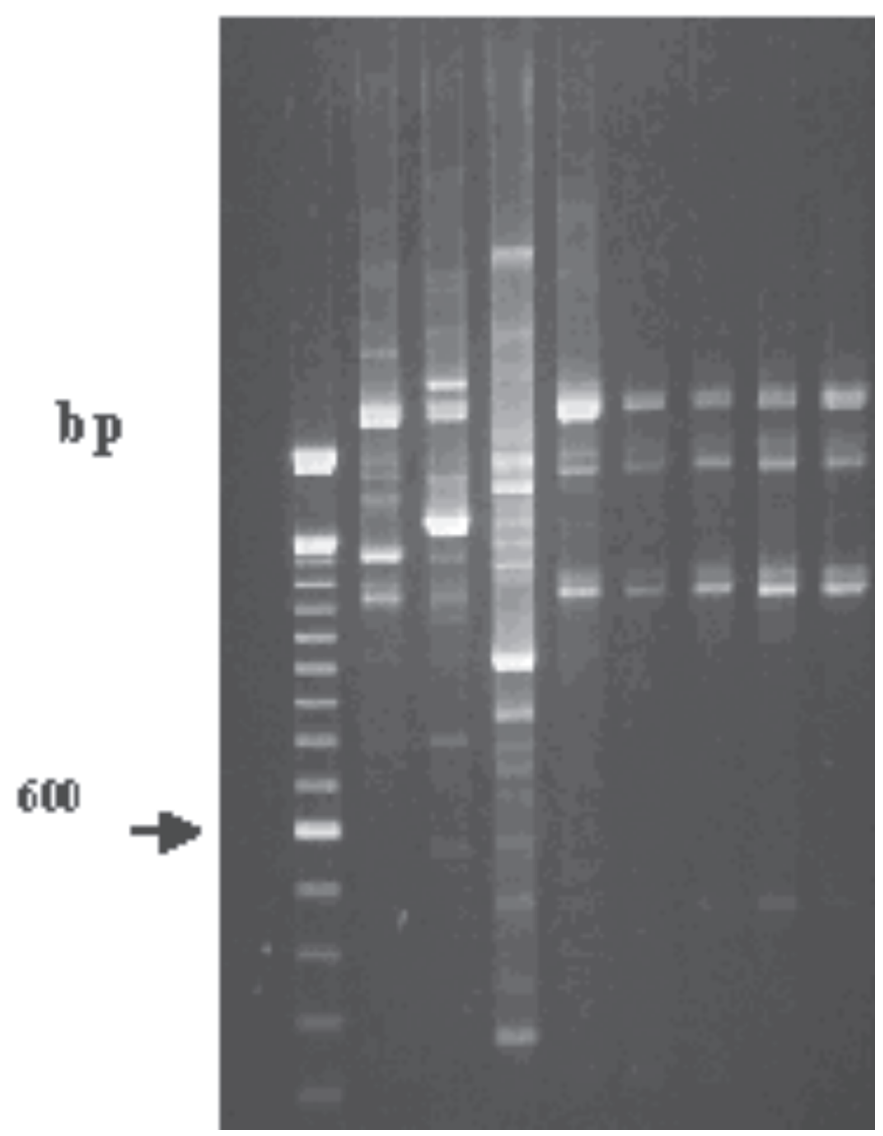

Fig.3. Gel de agarose 1,5\% dos produtos do RAPD-PCR. Linhas, $\mathrm{M}=$ "100 bp DNA ladder"; $1=B m$ 01; $2=B m$ 02; 3 $=B m 03 ; 4=B m 04 ; 5=B m 05 ; 6=B m 06 ; 7=B m 07 ; 8$ $=B m 08$.

Devido à importância para a sanidade animal e saúde pública, a tipagem molecular como instrumento de análise epidemiológica têm grande significância no que se refere a futuros programas de controle e profilaxia desta zoonose (Al-Ani \& Roberson. 2007). Estes métodos de tipagem têm vasta utilização e podem ser aplicados em futuros trabalhos com o objetivo de corrigir as lacunas existentes, como o estudo comparativo da tipagem molecular das amostras de B. mallei ambientais com as amostras isoladas de casos clínicos.

\section{CONCLUSÕES}

Foram comprovadas pequenas diferenças fenotípicas relativas à caracterização bioquímica das amostras de Burkholderia mallei isoladas de eqüídeos com mormo procedentes dos estados de Pernambuco e Alagoas não associadas com as variações genotípicas;

Existem diferenças genotípicas expressas no perfil molecular (Ribotipagem-PCR e RAPD) das amostras estudadas, demonstrando uma heterogeneidade que está relacionada com a procedência das amostras, indicando a infecção dos animais por diferentes isolados; 
O polimorfismo do DNA confirma a heterogeneidade do perfil ribotípico dos isolados estudados.

\section{REFERÊNCIAS}

Al-Ani F.K., Al-Rawashdeh O.F., Ali A.H. \& Hassan F.K. 1998. Glanders in horses: Clinical, biochemical and serological studies in Iraq. Veterinarski Arhiv 68(5):155-162.

Al-Ani F.K. \& Roberson J. 2007. Glanders in horses: A review of the literature. Veterinarski Arhiv 77:203-218.

Amemiya K., Bush G.V., Deshazer D. \& Waag D.M. 2002. Noviable Burkholderia mallei induces a mixed Th1 and Th2-like cytokine response in BALB/c Mice. Infect. Immun. 70(5):117-125.

Bauernfeind A., Roller C., Meyer D., Jungwirth R. \& Schneider I. 1998. Molecular procedure for rapid detection of Burkholderia mallei and Burkholderia pseudomallei. J. Clin. Microbiol. 36(9):2737-2741.

Benter T., Papadopoulos S., Manns M. \& Poliwada H. 1995. Optimization and reproducibility of random amplified polymorphic DNA in human. Anal. Biochem. 230:92-100.

Blancou J. 1994. Les anciennes methodes de surveillance et de controle de la morve. Bulletin Societé Vétérinaire Prat. de France 78(1):3554.

Campbell M., Mahenthiralingam E. \& David P. 2000. Evaluation of Random Amplified Polymorphic DNA Typing of Pseudomonas aeruginosa. J. Clin. Microbiol. 38:4614-4615.

Charlton B.R., Bickford A.A., Walker R.L., Yamamoto R. 1999. Complementary randomly amplified polymorphic DNA (RAPD) analysis patterns and primer sets to differentiate Mycoplasma gallisepticum strains. J. Vet. Diagn. Invest. 11:158-161.

Chen K.H. \& Chen T.A.A. 1995. Novel method for cloning DNA of plantpathogenic mycoplasmalike organisms. Can. J. Microbiol. 41:753-757.

Collier M.C., Stock F. \& Degirolami P.C. 1996. Comparison of PCRbased approaches to molecular epidemiologic analysis of Clostridium difficile. J. Clin. Microbiol. 34:1153-1157.

Debast S.B., Melchers W.J., Voss A., Hoogkamp-Korstanje J.A. \& Meis J.F. 1995. Epidemiological survey of an outbreak of multi-resistant Serratia marcecens by PCR-fingerprinting. Infections 23:267-271.

Dungworth D.C. 1993. Glanders, p.553-555. In: Jubb K.V.F., Kennedy P.C. \& Plamer N. (Eds), Pathology of Domestic Animals. Vol.2. $4^{\text {th }}$ ed. Academic Press, San Diego.

Farber J.M. 1996. An introduction to the hows and whys of molecular typing. J. Food Prot. 59:1091-1101.

Fritz D.L., Vogel P., Brown D.R., Deshazer D. \& Waag D.M. 2000. Mause model of sublethal and leihal intraperitoneal glanders (Burkholderia mallei). Vet. Pathol. 37:626-636.

Grattard F., Berthelot P., Reyrolle M., Ros A., Etienne J. \& Pozzetto B. 1996. Molecular typing of nosocomicalstrains of Legionella pneumophila by arbitrarily primed PCR. J. Clin. Microbiol. 34(6):15951598.

Godoy A.P.O., Miranda M.C.B., Paulino L.C. Mendonça S., Ribeiro M.L. \& Pedrazzoli Jr P. 2007. Análise das impressões digitais de DNA e de fatores de virulência de linhagens de Helicobacter pylori. Arq. Gastroenterol. 44: 107-112

Kostmam J.R., Edlind T.C., Lipuma J.J. \& Stull T.L. 1992. Molecular epidemiology of Pseudomonas cepacia determined by polimerase chain reaction ribotyping. J. Clin. Microbiol. 30:2082-2087.

Kurata N., Nagamura K. \& Yamamoto K. 1994. A 300 kilobase interval genetic map of rice including 283 expressed sequences. Nat. Genet. 8:365-372.
Langenegger J., Döbereiner J. \& Lima A.C. 1960. Foco de mormo (Malleus) na Região de Campos, estado do Rio de Janeiro. Arqs Inst. Biol. Animal, Rio de J., 3:91-108.

Lawrence L.M., Harvey J. \& Gilmour A. 1993. Development of a random amplification of polimorphic DNA typing method for Listeria monocytogenes. Appl. Environ. Microbiol. 59:3117-3119.

Leelayuwat C., Romphruk A., Lulitanond A., Trakulsomboon S. \& Thamlikitkul V. 2000. Genotype analysis of Burkholderia pseudomallei using randomly amplified polymorphic DNA (RAPD): Indicative of genetic differences amongst environmental and clinical isolates. Acta Tropica. 77:229-237.

Mattar G.M., Khneisser I.A. \& Abdelnoor A.M. 1996. Rapid laboratory confirmation of human brucellosis by PCR analysis of a target sequence on the 31-kilodalton Brucella antigen DNA. J. Clin. Microbiol. 34:477478.

Mota R.A., Santos F.L., Castro F.J.C. \& Cavalcante M.I. 1999. Mortalidade de eqüídeos criados na Zona da Mata dos Estados de Pernambuco e Alagoas: aspectos clínicos, epidemiológicos e anátomohistopatológicos. Anais IV Congresso Pernambucano de Medicina Veterinária, Recife, 1:251-252.

Mota R.A., Brito M.F., Castro F.J.C. \& Massa M. 2000. Mormo em eqüídeos nos estados de Pernambuco e Alagoas. Pesq. Vet. Bras. 20(4):155-159.

Pimentel W. 1938. História e organização do serviço veterinário do exército. Revta Militar Med. Vet. 1(4):283-322.

Pritchard D.G. 1995. Glanders. Equine Vet. Educ. 7(1):29-32.

Rabelo S.S.A. 2003. Infecção natural pela Burkholderia mallei em muares (Equus asinus caballus) procedentes da Zona da Mata do estado de Pernambuco: aspectos clínicos, hematológicos e bioquímicos séricos. Tese de Doutorado em Ciência Veterinária, Universidade Federal Rural de Pernambuco, Recife. 55p.

Sambrook J. \& Russel D. W. 2001. Molecular Cloning: A laboratory manual, CHS Press, 02:2100.

Selender R.K., Caugant D.A. \& Ochman H. 1986. Methods for multilocus enzyme eletrophoresis for bacterial population genetics and sistematcs. Appl. Environ. Microbiol. 51:873-874.

Sharrer G. T. 1995. The great glanders epizootic. Agric. Hist. 69:79-97

Silva L.B.G. 2003. Diagnóstico microbiológico do mormo em eqüídeos e infecção experimental em cobaias (Cavia porcellus) pela Burkholderia mallei: aspectos clínicos e anátomo-histopatológico. 2003. Tese de Doutorado em Ciência Veterinária, Universidade Federal Rural de Pernambuco, Recife. 70p.

Sorroel T.C., Chen S.C.A., Ruma P., Malik R. \& Pfeiffer T.J. 1996. Concordance of clinical and enviromental isolates of Criptococcus neoformans var. gattii by random amplification of polymorphic DNA analysis and PCR fingerprinting. J. Clin. Microbiol. 34:1253-1260.

Tyler S.D., Strathdee C.A., Rozze K.R. \& Jhonson W.M. 1995. Oligonucleotide primers designed to differentiate pathogenic pseudomonads on the basis of the sequencing of genes coding for 16S-23S rRNA internal transcribed spacers. Clin. Diagn. Lab. Immunol. 4(2):448453.

Williams J.G.K., Kubelik A.R., Livak K.J., Rafalski J.A. \& Tingly S.V. 1990. DNA polimorphims amplified by arbitary primers are usefeld as genetic markers. Nucleic Acids Res. 18:6531-6535.

Wuthiekanum V., Smith M.D., Dance D.A.B., Walsh A.L., Pitt T.L. \& White N.J. 1996. Biochenical characteristics of clinical and environmental isolates of Burkholderia pseudomallei. J. Med. Microbiol. 45: 408-412.

Welsh J. \& McClelland M. 1990. Fingerprinting genomes using PCR with larbitrary primers. Nucleic Acids Res. 18:7213-7218. 